\title{
ЭКОЛОГИЧЕСКОЕ СОСТОЯНИЕ АПШЕРОНСКОГО ПОЛУОСТРОВА
}

\author{
${ }^{1}$ Мусаев Ровшан Али оглы, ведущий научный сотрудник \\ ${ }^{2}$ Карим Дюкавиди Тарзило, докторант кафедры сочуиологии и психологии \\ ${ }^{1}$ Института Физики при Бакинском Государственном Университете \\ ${ }^{2}$ Бакинский Государственный Университет
}

DOI: https://doi.org/10.31435/rsglobal_ws/30082018/6069

\section{ARTICLE INFO}

Received: 24 July 2018

Accepted: 20 August 2018

Published: 30 August 2018

\section{KEYWORDS}

ecology, radioactive pollution, oil waste, environment, immunity system. \begin{abstract}
This article investigates the areas exposed to radioactive contamination in the oil-producing fields of the six regions of the Republic of Azerbaijan covering the Apsheron peninsula. As a result of these studies, radioactive crisis areas where discovered, and the specific map was created.

The semi-empiric formulas were used to estimate the concentration of harmful radon gas which is the fission product of radium isotope-one of the radio-isotopes causing irradiation. It is recommended that radioactive waste in the area be used for road transport in accordance with the norms.
\end{abstract}

Citation: Мусаев Ровшан Али оглы, Карим Джавиди Тарзило. (2018) Ekologicheskoe Sostoyanie Apsheronskogo Poluostrova. World Science. 8(36), Vol.2. doi: 10.31435/rsglobal_ws/30082018/6069

Copyright: (C 2018 Мусаев Ровшан Али оглы, Карим Джавиди Тарзило. This is an open-access article distributed under the terms of the Creative Commons Attribution License (CC BY). The use, distribution or reproduction in other forums is permitted, provided the original author(s) or licensor are credited and that the original publication in this journal is cited, in accordance with accepted academic practice. No use, distribution or reproduction is permitted which does not comply with these terms.

В науке до настоящего времени известно 4,7 млн. вредных химических и радиоактивных веществ. Из них только 3 тысячи исследованы с точки зрения вредного воздействия на человеческий организм на уровне токсикологии и генетики. $[2,4]$

Основной причиной загрязнения окружающей среды является воздействие природных и антропогенных факторов. В результате влияния этих факторов в настоящее время происходят процессы глобальных изменений в природной среде. Поэтому наблюдается изменение климата, меняется химический состав атмосферы, усиливается воздействие парниковых эффектов, выпадают кислотные осадки, изменяется размер озонового слоя, а также нарушается круговорот воды в природе, развивается массовое обезлесение, усиливается эрозия земли и падение естественного плодородия почв, возрастают стихийные бедствия, сокращается генофонд планеты $[1,9]$.

Искусственное вмешательство в природную среду нарушает не только циклические аспекты самой природы, но и также порождает совершенно новые проблемы. Эти проблемы коренным образом связаны не только с загрязнением, но и также порождают новые болезни и вместе с тем новые проблемы, связанные с биомедицинскими нарушениями. В этом плане можно отметить, что в целом происходит деградация всех природных аспектов, контролирующие и обеспечивающие условия, необходимые для поддержания жизненных циклов. На рис.1 указан круговорот загрязнения в ноосфере. [2]

В Азербайджане наиболее остро существуют аналогичные, экологические проблемы, связанные с нефтеразведкой, добычей, обработкой и сохранением этих продуктов. Основным источником и причиной является добывание нефти на Апшеронском полуострове и в Каспийском море. Известно, что первая нефтяная скважина бурилась в 1859-ом году в Пенсильванском штате Америки [3, 11]. 
В Азербайджанской республике разработка нефтегазовых месторождений производится на Апшеронском полуострове свыше 100 лет. Эти промысловые объекты являются источником загрязнения нефтегазовыми продуктами. Месторождения этих продуктов располагаются не только на суше Апшеронского полуострова, но и прилегающей акватории Каспийского моря. Общая площадь Апшеронского полуострова составляет 281000 га. Из них 7,8\% участка занимается нефтегазовой промышленностью.

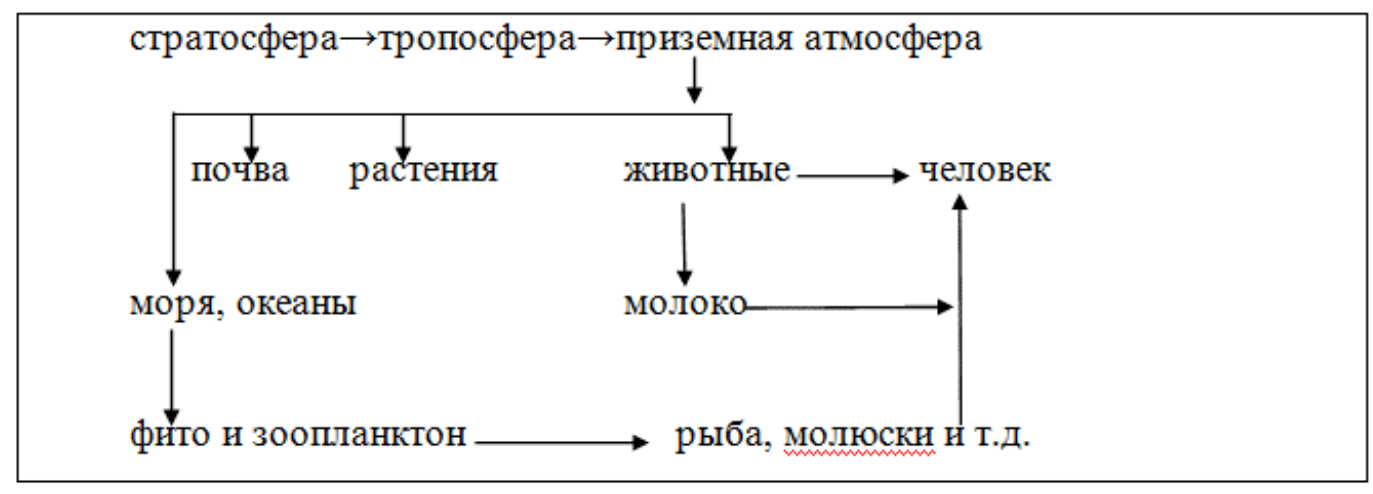

Рис.1. Цикл загрязнения в ноосфере

По данным Статистического Комитета по 1871-2004-й год в Азербайджане добыто более 1,2 млрд. тонн нефти. Из Апшеронской нефти вырабатываются продукты более 100 наименований. По состоянию на 1 января 2000 года общий фонд скважин на нефтяных промыслах составляет более 10000 единиц. Более 65\% общих нефтепродуктов добывается на суше. Основной состав нефти состоит из ненасыщенных алифатических и гидроароматических углеводородов от $\mathrm{C}_{5}$ до $\mathrm{C}_{70}$ и содержит $80 \div 85 \% \mathrm{C}, 10 \div 14 \% \mathrm{H}, 0,001 \div 7 \% \mathrm{~S}, 001 \% \mathrm{~N}, 0,01 \div 6,9 \%$ $\mathrm{O}_{2}$ и другие соединения. Нефть способна выпускать слабую флюоресценцию. Основные компоненты нефти подразделяются на 4 класса:

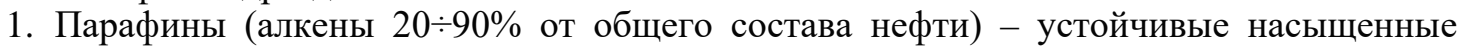
соединения $\mathrm{C}_{\mathrm{n}} \mathrm{H}_{2 \mathrm{n}+2}$, молекулы которых выражены прямой или разветвлённой (изоалканы) целью атомов углерода. Парафины включая газы: метан- $\mathrm{CH}_{4}$, этан- $\mathrm{C}_{2} \mathrm{H}_{6}$, пропан- $\mathrm{CH}_{2} \mathrm{CH}_{2} \mathrm{CH}_{3}$ и другие жидкие соединения с $5 \div 17$ атомов углерода - твёрдыми веществами.

2. Циклопарафины - нафтены, насыщенные циклические соединения $\mathrm{C}_{n} \mathrm{H}_{2 n}$ с $5 \div 6$ атомами углерода в кольце нафтены составляет $30 \div 60 \%$ от общего состава нефти. Нафтены очень устойчивы и плохо поддаются биоразложению.

3. Ароматические углеводороды - $20 \div 40 \%$ от общего состава нефти -ненасыщенные циклические соединения ряда бензола $\left(\mathrm{C}_{6} \mathrm{H}_{6}\right)_{n}$. В нефти присутствуют летучие соединения с молекулой в виде одинарного кольца $-\mathrm{C}_{6} \mathrm{H}_{6}$, тлуол - $\left(\mathrm{CH}_{3}\right)_{2}$, ксилол- $\mathrm{C}_{6} \mathrm{H}_{4}$, нафталин- $\mathrm{C}_{10} \mathrm{H}_{8}$

4. Олефины - алкены- $\mathrm{C}_{n} \mathrm{H}_{2 n+2}$ до $10 \%$ от общего состава нефти. Алкены, ненасыщенные нециклические соединения с одним или двумя атомами водорода у каждого атома углерода в молекуле, имеющей прямую разветвлённую цепь.

В зависимости от географического месторождения нефти существенно различаются по своему составу. Так, Бакинская и Калифорнийская преимущественно нафтеновые, Пенсильванская и Кувейтская нефтепарафинистые, остальные - нефти промежуточных типов [10].

Загрязнение окружающей среды продуктами нефти происходит в процессе бурения, добычи, подготовки и транспортировки. Основным элементом загрязнения является нефть, нафтен, нефтяной шлам, пластовые и сточные воды, содержащие химические вещества. В результате загрязнения нефтепродуктами страдает почвенный-растительный покров, что приводит к изменению естественного состава растительной пищи. Изменяется флора и фауна. Загрязнение и засорение подземных грунтовых вод происходит в основном за счёт скважин законтурного заводнения на промыслах Сабунчинефть, Сураханынефть, Хазарнефть, Бинагадинефть, Гарадагнефть, Сабаильнефть. Законтурное заводнение влияет на подземные воды. Нефтяные воды путём инфильтрации в грунт смешиваются с грунтовыми водами, искусственно повышая уровень последних и сильно увеличивая их минерализацию. В результате содержание гумуса в земле уменьшается и растительный мир получает 
экологический удар. В Апшеронском полуострове насчитываются запасы вод около 10 млрд м ${ }^{3}$. При бурении Азнефть извлекает с нефтью более 40 млн м ${ }^{3}$ пластовых вод. Эти жёсткие воды содержат $\mathrm{NaCl}, \mathrm{CCl}, \mathrm{MgCl}, \mathrm{J}, \mathrm{Br}$, соду и др. Но несмотря на вышесказанное губительно на растительный мир действует один из нефтепродуктов Нафтен. На некоторых НГДУ вблизи нефтяной вышки глубина нефтезагрязнение доходит до 60-100 см., а уровень грунтовых вод доходит до $130 \mathrm{~cm}$. В связи с этим величина гумуса в метровой глубине уменьшается до $1 \%$, и это вредно для растительного мира. Имеющиеся данные показывают, что параллельно изменяется азотистый состав почвы. Известно, что при бурении скважин в окружающую среду в составе пластовых вод выбрасываются ещё радиоактивные элементы, которые создают радиоактивное загрязнение. В связи с этим нами в течение нескольких лет произведены исследования о радиоактивном загрязнении в 6-и районах и бывших Йодовых заводах Апшеронского полуострова. Эти районы захватывают Сураханский, Сабунчинский, Бинагадинский, Хазарский, Сабаиль, Гарадагский НГДУ, а также бывший Йодовый завод. На рисунке 2 показаны карты районов Апшеронского полуострова, загрязнённые нефтерадиоактивными продуктами. В этих измерениях использовали радиометр РКСБ-4 и спектрометр АИ-1024 с детектором $\mathrm{NaJ}(\mathrm{Tl})$. Измерения проводились во всех шести НГДУ нефтегазодобывающих участках и его окружениях, а также в окружениях Йодового завода на территории Сабунчинского района. Основные высокоинтенсивные загрязнённые точки зафиксированы на нефтеловушках и окружающих лужайках, нефтезапасных цистернах и нефтекоммуникационных линиях. В самых наиболее радиационноопасных зонах взяты образцы весом 300 $\div 500$ г. с целью спектрального анализа на спектрометре.

При анализе выявлена самая большая концентрация радиоактивных изотопов $\mathrm{U}, \mathrm{Ra}, \mathrm{Th}$, $\mathrm{Cs}, \mathrm{K}$. Концентрация этих изотопов на каждый грамм взятых образцов составляет изотопы: урана $-(20 \div 30) \times 10^{-6} г$; радия - $(20 \div 80) \times 10^{-12} \Gamma$; тория - $(30 \div 190) \times 10^{-6} \Gamma$; цезия - $(30 \div 60) \times 10^{-6} \Gamma$; калия $-(40 \div 50) \times 10^{-6}$ г. И общая относительная интегральная доза по радиоактивности показана на таблице 2. На таблице даны измеренные средние данные в относительных единицах по соответствии нормам радиоактивной безопасности в 6-и нефтедобывающих районах Апшеронского полуострова. Самые завышенные дозы по нормам выявлены в районах: Гарадагский - 238 раз, Хазарский -232 раза и бывший Йодовый завод - 248 раз. Известно, что при распаде Ra-226 выделяется ядовитый изотоп радона. Газовый изотоп Радона распространяется в биосфере в виде пара. Этот пар сильно действует на дыхательную систему, печень, почки. Самый существенный удар получает в организме необходимый гормональный орган - это щитовидная железа. Гормон тироксина в щитовидной железе влияет на мозговой гормон серотонина. В результате появляются головные боли и начинается депрессия. У человека ослабляется иммунная система и он впадает в психический кризис. $[5,6,8,12]$

Для практической цели нами предложена методика для расчета газовой концентрации радиоактивного изотопа радона. Поскольку изотопы радия $(\mathrm{Ra})$ при распаде образуют самый долгоживущий изотоп - газовый радон Rn. B связи с этим нами предложена полуэмприческая формула для расчёта газового изотопа радона:

$$
\mathrm{C}_{\mathrm{n}}=\mathrm{C}_{0}\left[1-1,4 \mathrm{~T} \sqrt{D}+\mathrm{T}^{2} \mathrm{D}-0,45 \mathrm{~T}^{3} \mathrm{D} \sqrt{D}+0,16 \mathrm{~T}^{4} \mathrm{D}^{2}+\ldots\left(\frac{-1,4 T \sqrt{D}}{n}\right)\right] \cdot \mathrm{f}\left(\mathrm{K}_{\mathrm{i}}\right)
$$

$\mathrm{C}_{0}$ - начальная концентрация радона, образующегося в результате деления радия.

T - период полураспада изотопа радона;

$\mathrm{D}$-коэффициент диффузии радонового изотопа;

$\mathrm{f}\left(\mathrm{K}_{\mathrm{i}}\right)$ - кумулятивная поправка, учитывающая геометрию окружающей среды;

$\mathrm{C}_{\mathrm{n}}$ - конечная концентрация изотопа радона;

Для расчёта применяется коэффициент диффузии изотопа $\mathrm{Rn}: ~ 0,1 \mathrm{~cm}^{2} / \mathrm{c}$ в воздухе, $10^{-5} \mathrm{~cm}^{2} / \mathrm{c}-\mathrm{B}$ воде;

Эту формулу можно применять для практического расчёта радиоактивного газа радона. $[7,14]$

На рис.2 предлагаются экологические карты по загрязнению радиоактивными веществами и нефтепродуктами. Показаны знаки условного обозначения. 


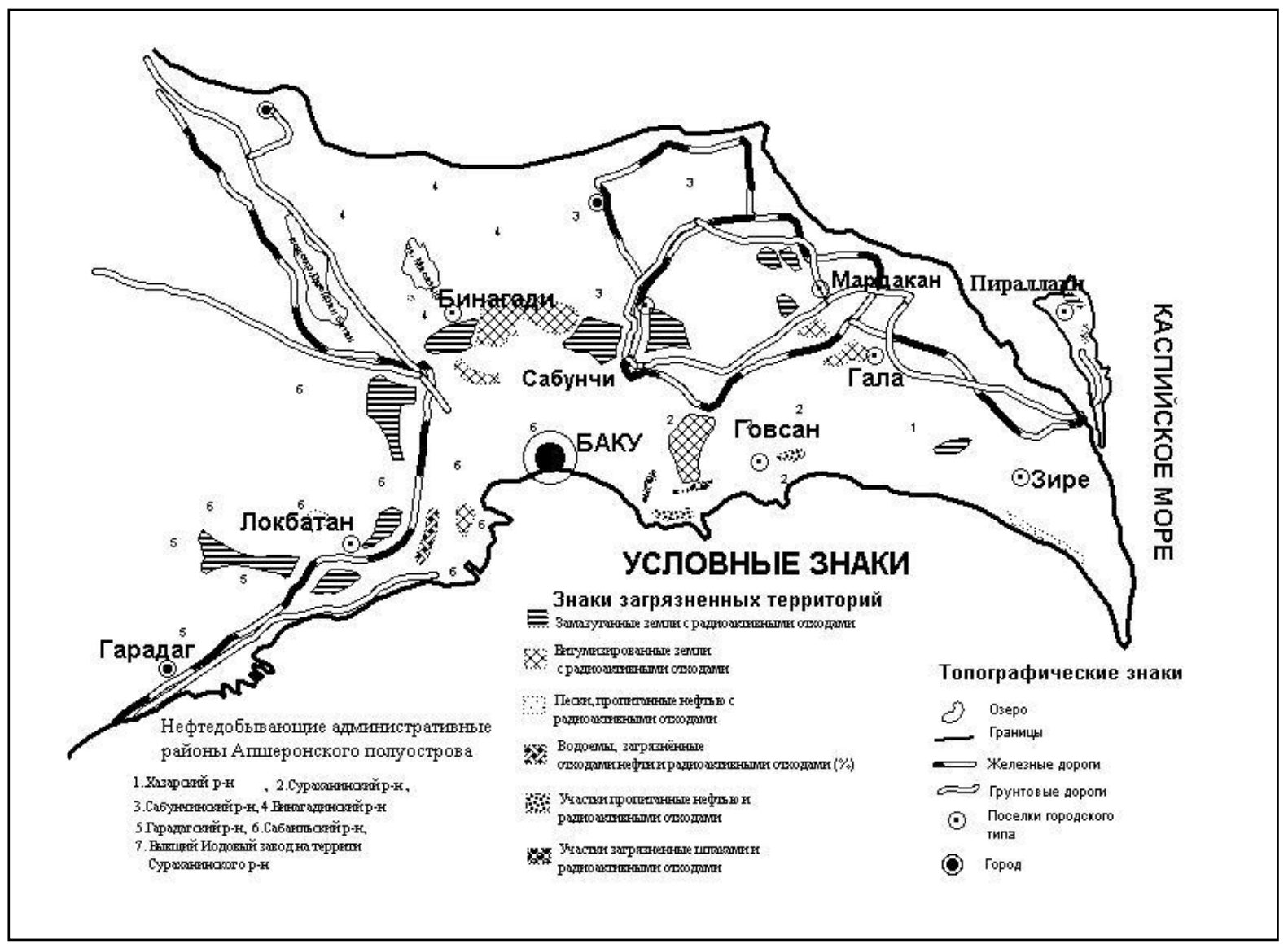

Рис. 2. Карта-схема загрязненных территорий нефтедобывающих районов Апшеронского полуострова с радиоактивными веществами

Относительный уровень повышенных норм радиоактивной безопасности показан в таблице 1.

По результатам исследований выявлены измеренные средние данные в относительных единицах по соответствии нормам радиоактивной безопасности в 6-и нефтедобывающих районах Апшеронского полуострова:

Сураханынефть - 25,7 \%

Сабунчинефть - 10,3 \%

Бинагадинефть - 25,2 \%

Хазарнефть - 8,2 \%

Сабаильнефть - 26,3\%

Гарадагнефть - 4,99 \%

Бывший Йодовый завод - 82 \%

Самые большие радиоактивные отходы были накоплены на нефте-ловушках, на стыках нефтяных трубопроводов, коммуникационных соединениях нефтяных цистерн и у самих нефтезапасающих цистернах.

Подобные проблемы с радиоактивными загрязнениями существуют и в других нефтедобывающих странах, в том числе и в США $[10,15]$.

Таблица 1. Сравнительная таблица по радиоактивным загрязнениям Апшеронского полуострова и некоторых нефтедобывающих Штатах Америки.

\begin{tabular}{|c|c|c|c|c|}
\hline $\begin{array}{l}\text { Место } \\
\text { расположения }\end{array}$ & ${ }^{238} \mathrm{U} \cdot \Gamma / \Gamma$ & ${ }^{232} \mathrm{Th}, \Gamma / \Gamma$ & ${ }^{232} \mathrm{Ra}, \Gamma / \Gamma$ & ${ }^{40} \mathrm{~K}, \%$ \\
\hline $\begin{array}{l}\text { Азербайджанская } \\
\text { Республика, } \\
\text { Апшеронский } \\
\text { полуостров }\end{array}$ & $(20 \div 30) \cdot 10^{-6}$ & $(30 \div 190) \cdot 10^{-6}$ & $(20 \div 80) \cdot 10^{-12}$ & $(40 \div 50) \cdot 10^{-6}$ \\
\hline $\begin{array}{l}\text { США, } \\
\text { штаты Луизиана } \\
\text { Флорида }\end{array}$ & $\begin{array}{l}(3 \div 5) \cdot 10^{-6} \\
(2 \div 5) \cdot 10^{-6}\end{array}$ & $\begin{array}{l}(10 \div 30) \cdot 10^{-6} \\
(10 \div 20) \cdot 10^{-6}\end{array}$ & $\begin{array}{l}(1 \div 5) \cdot 10^{-12} \\
(2 \div 5) \cdot 10^{-12}\end{array}$ & $\begin{array}{l}(5 \div 15) \cdot 10^{-6} \\
(5 \div 5) \cdot 10^{-6}\end{array}$ \\
\hline
\end{tabular}


Из этой таблицы видно, что радионуклидные загрязнения на Апшеронском полуострове в 6-50 раз выше, чем в нефтедобывающих штатах США.

В результате обширных исследований выявлено, что из общей площади 281000 га Апшеронского полуострова слабо нарушен почвенно-растительный покров; $28 \%$ - территории рельеф почвы сильно изменён, т. е. из этого рельефа почвенно-растительный покров находится в плохом состоянии, $6 \%$-удовлетворительное и $7 \%$ из них в катастрофическом состоянии.

С целью профилактики здоровья работающих в НГДУ (нефтегазодобывающие участки) изучены действия радиоактивности на иммунную систему и психическое состояние. Проведено медицинское исследование работающих в НГДУ. Работы провели Национальный институт по медицинской профилактике при Министерстве Здравоохранения Азербайджанской Республики. Для исследования взяты анализ крови; рассчитано абсолютное число лейкоцитов и лимфоцитов, рассчитано абсолютное и относительное число тромбообразующих лимфоцитов в крови, активность нейтрофилов в процессе латекс-фагацитозе, уровень лизосимов в слюне и проведены тесты на психологическое состояние работников. Всего в эксперименте участвовали 35 человек. В исследовании периферической крови выявлено уменьшение лейкоцитов на $20 \%$ относительно контроля число т-лимфоцитов (контроль $-7,1 \div 0,4) \cdot 10^{9} /$ л. Проверено психологическое состояние работающих и выявлено, что их состояние почти не изменилось. Для поддержания здоровья работающих в НГДУ предложен соответствующий пищевой рацион и дан препарат «Мадаш Праш», изготовленный из морского обитателя - мидии. В результате лечения обнаружено увеличение активности иммунной системы. [7]

В мире существует несколько способов чистки и захоронения радиоактивных отходов. Из них более распространёнными считаются: рекультивации и обезвреживания загрязнённых участков; испарение и очищение загрязнённой воды методом инфильтрации и затем загрузка в бетонный контейнер для захоронения твердой части радиоактивных отходов; внедрение специальных микробов для чистки загрязнённых участков; перекачка загрязненной воды в старую, использованную скважину. [11]

В результате анализа имеющихся данных нами предложена математическая методика расчёта опасного радиоактивного газа радона в почвах и жидкости. А также предлагаем создать передвигающиеся миниустановки для разделения компонентов в зависимости от их размеров и твёрдости, доведения до безопасного уровня, а затем использовать их для прокладки дорог.

Исходя из вышеизложенных экспериментов можно заключить, что такое острое экологическое состояние требует разумного вмешательства для сохранения экологической стабильности в природной среде Азербайджана.

В заключении необходимо отметить, что проблема экологии одна из глобальных, классических проблем современности.

Таблица 2. Загрязнённые радиоактивными отходами нефтедобывающие районы Апшеронского полуострова

\begin{tabular}{|c|c|c|c|c|c|c|c|c|c|c|c|}
\hline № & \begin{tabular}{|l} 
Нефтедобывающие \\
районы \\
Апшеронского \\
полуострова
\end{tabular} & 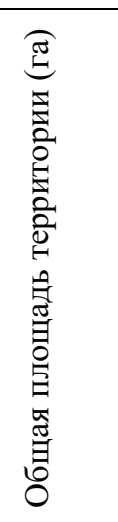 & 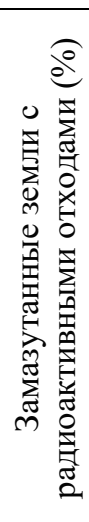 & 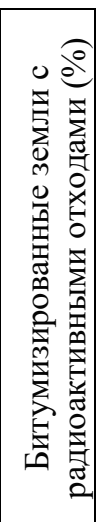 & 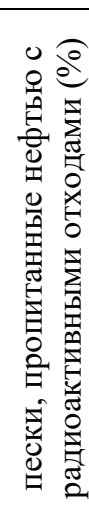 & 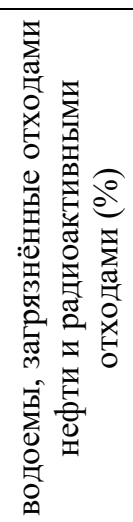 & 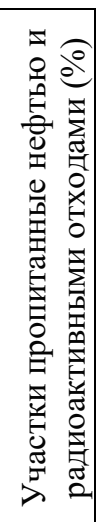 & 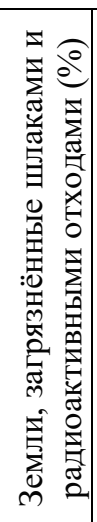 & 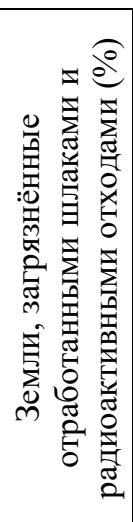 & 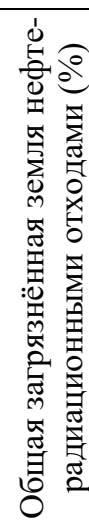 & 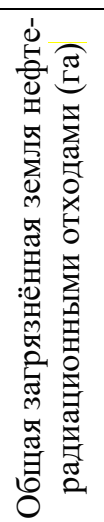 \\
\hline 1 & Хазарский р-н & 40360 & 2 & 1,9 & 0,9 & 1,2 & 1 & & 1,2 & 8,2 & 330,95 \\
\hline 2 & Сураханский р-н & 12110 & 11 & 2,3 & 1,6 & 0,8 & 9,9 & & & 25,7 & 311,5 \\
\hline 3 & Сабунчинский р-н & 24430 & 2,9 & 3,5 & & 1,1 & 2,8 & & & 10,3 & 251,6 \\
\hline 4 & Бинагадинский р-н & 15780 & 7,3 & 10,3 & & 1,7 & 6,2 & & & 25,2 & 397,6 \\
\hline 5 & Гарадагский р-н & 108370 & 1 & 2,5 & 0,09 & 0,6 & 0,8 & & & 4,99 & 540,7 \\
\hline 6 & Сабаильский р-н & 2800 & 16 & 4,5 & & & 14 & 1,8 & & 26,3 & 73,6 \\
\hline 7 & $\begin{array}{l}\text { Бывший Йодовый } \\
\text { завод Сураханского } \\
\text { района }\end{array}$ & 1 & 82 & & & & & & & 0,82 & 0,82 \\
\hline
\end{tabular}




\section{ЛИТЕРАТУРА}

1. Р. М. Алексахин - Радиоактивное загрязнение почв как тип их деградации//Журнал Почвоведение, 2009 №12, с.1487-1498

2. Современные проблемы радиационных исследований. Под ред. Л. Х.Эйдуса. М.Наука.1972г.

3. Вредные химические вещества. Радиоактивные вещества. Справочник. Под. ред. Л. А. Ильин, В. А. Филов. Ленинград, Изд-во «Химия». 1990 г.

4. А. М. Владимиров, Ю. И. Ляхин, Л. Т. Матвеев. Охрана окружающей среды. Ленинград, 1991 г.

5. А. М. Кузин. Невидимые лучи вокруг нас. Москва. Наука. 1980 г.

6. Н. На. Вычислительные методы решения прикладных граничных задач. М., Мир. 1982 г.

7. Р. А. Мусаев. Модель распространения радонового газа на окружающую среду// Материалы конференции (27-28 Апрель, 2007) - Проблемы прикладной биологии. Бакинский Государственный Университет, 2007 г. с.23-25

8. А. М. Кузин и др. Радиационная биология//Журнал Радиоэкология. 1993 г. Т.33. вып.6 с.816-853

9. Перенос радиации в рассеивающих и поглощающих атмосферах. Под ред. Жаклин Ленобль Л.1990 г.

10. Таригулиев А. Ф. Автореферат, Казахстан, г. Алмата, 2018 г.

11. Селивановская, Р. Х. Гумерова, О. Р. Бадрутнутдинов. Влияние радиоактивных отходов нефтедобывающего комплекса на микробное сообщество серой лесной почвы.// Вестник Российского Университета Дружбы Народов №4, 2011 год, страница 85-93

12. Р. А. Мусаев, А. Г.Алиев, И. А.Омаров. Влияние малых доз на состав крови./ Материалы конференции «Проблемы безопасности жизненной деятельности людей. (4-5 февраль 1999 г.). Типография «Чашоглу», г. Баку. С.38-39

13. Багирова С. М., Казымова С. А., Сулейманова С. Ф. Действие радиационных излучений на иммунную систему нефтяников и препараты, укрепляющие иммунитет.// Материалы конференции «Проблемы безопасности жизненной деятельности людей. (4-5 февраль 1999 г.). Типография «Чашоглу», г. Баку. стр.79-82

14. Мусаев Р. А., Оценка уровня загрязнения атмосферы вредными примесями.// Известия Бакинского Государственного Университета, 2002, №2, стр. 79-85.

15. Радиоактивные загрязнения //www/vuzlit.ru/13421-44 